Article

\title{
From Home to Community: Reflecting Emotions Related to Mobility
}

\author{
Suvi Holmberg * and Jenni-Mari Räsänen \\ Faculty of Social Sciences, Tampere University, Finland; E-Mails: suvi.holmberg@tuni.fi (S.H.), \\ jenni-mari.rasanen@tuni.fi (J.-M.R.) \\ * Corresponding author
}

Submitted: 30 March 2021 | Accepted: 24 May 2021 | Published: 26 August 2021

\begin{abstract}
This study investigates how clients' emotions are invoked and reflected in client-worker interactions and the meanings they have regarding leaving home. We concentrate on floating support work, which aims to support people suffering from mental health and substance abuse-related issues to improve their living in the community. Our theoretical framework is based on the geography of emotions, and we draw on both the interactional and relational approaches thereto. The research material is gathered from Finland and England. We draw on mobile ethnographic and discursive approaches, and our data consists of transcriptions and field notes gathered during floating support visits $(N=19)$ that took place either at or outside of a client's home. Our findings demonstrate how the connections between places and emotions, the emotions connected to leaving one's home, the emotions reflected while being out in the community, and the reflections of emotions after being out in the community are constructed and reflected in client-worker interactions. The study highlights that these emotions are a necessary and demanding part of promoting clients' social inclusion in the context of floating support work.
\end{abstract}

\section{Keywords}

emotions; floating support; from home to community; mental health; mobility; substance abuse

\section{Issue}

This article is part of the issue "Home- and Community-Based Work at the Margins of Welfare: Balancing between Disciplinary, Participatory and Caring Approaches" edited by Kirsi Juhila (Tampere University, Finland), Cecilia Hansen Löfstrand (University of Gothenburg, Sweden) and Johanna Ranta (Tampere University, Finland).

(C) 2021 by the authors; licensee Cogitatio (Lisbon, Portugal). This article is licensed under a Creative Commons Attribution 4.0 International License (CC BY).

\section{Introduction}

Recent decades have seen a transition in long-term mental health and psychiatric services, which now generally take place at community-based rather than institutionbased facilities (De Heer-Wunderink et al., 2012, p. 1102). In the literature, this development has been conceptualised as 'deinstitutionalisation' (Fakhoury \& Priebe, 2007). Another term, 'home turn,' outlines how institutional services targeting people living at the margins of welfare have been replaced by offering support and services in their homes and communities (Hall et al., 2021). These developments have led to the increased prevalence of working practices that focus on floating or mobile support (e.g., Juhila, Holmberg, et al., 2020; Ranta \& Juhila, 2020). As a whole, community-based ser- vices and 'home turn' are generally seen as responses to critiques targeted at large mental health and residential institutions, as well as office-based services (e.g., Hall et al., 2021).

The goals of deinstitutionalisation and home turn policies and practices are to advance the active citizenship of people living at the margins of society, strengthen their self-determination and autonomy, and emphasise their right to equal housing (Miettinen \& Teittinen, 2014; Tideman \& Tossebro, 2002). Another important goal is to enhance their social inclusion (De Heer-Wunderink et al., 2012, p. 1102) and social connectedness, which are said to be key strategies for improving the lives of people with mental health problems (Hare-Duke, 2017). Still, community-based services have been criticised for further marginalising people who are already isolated 
by bringing services into their homes (e.g., Kröger \& Leinonen, 2012; Tucker, 2010, p. 446). This becomes especially evident in cases where individuals don't want to leave their homes or participate in social, societal, and communal activities. Furthermore, Richardson (2019, pp. 36-42) states that the home environment can trap and isolate people. She argues that the home can be an emotionally and physically dangerous place if evaluated in terms of phenomena such as violence, abuse, or gender inequality. Conflicts in the home can threaten one's emotional, social, and physical health, but fears of these threats can also emerge when thinking about leaving home. Home is a place that provides security and comfort, and thus it is difficult to leave. However, spending a lot of time at home and being able to organise and manage one's home space has also been shown to promote a sense of inclusion and feelings of control and social normalcy, as some places outside the home can cause fear, pressure, and anxiety (Tucker, 2010, pp. 444-447).

According to Wong et al. (2014, p. 685), studies concerning the community and social integration of people, "in recovery from mental illness," have not focused enough on the social and relational dimensions of integration, including the ways that people acquire and re-establish membership in their various communities. It has been argued that mental health practitioners need to explore the emotional/cognitive, moral, and social competencies of people recovering from mental illness in order to best help them achieve community inclusion: Emotional competence is needed to develop reciprocal community relationships (Wong et al., 2014, pp. 690,693$)$.

This article focuses on situations where leaving home is somehow difficult due to mental and/or physical restrictions, loneliness, or a lack of social skills or knowledge of how to act in certain situations. These reasons are often connected to emotions; feelings of insecurity, fear, or anxiety, for example, can cause voluntary isolation.

Our goal is to demonstrate how clients' emotions are connected to leaving home and community engagement, and how these emotions are reflected in the interaction between clients and workers. We focus on client-worker interactions that support people in operating outside their homes and participating in activities in their communities. We define this kind of floating support work as going out into the community. Floating support work takes place "in people's own homes to support their living in the community, prevent evictions, and, thus, reduce the risk of homelessness" (Juhila, Holmberg, et al., 2020 , p. 1). These services are diverse and can include everything from practical help and guidance on everyday issues to more therapeutic conversations to walks in a nearby community (Juhila, Hansen Löfstrand, \& Raitakari, 2020). In this article, we ask two specific questions:

1. How are clients' emotions invoked and reflected in client-worker interactions?
2. What kinds of meanings do these emotions have in relation to leaving home?

\section{Everyday Mishmash of Emotions}

Every action we take in daily life is connected to emotions. The people we interact with, the goods we use, and the environments and spaces we operate in evoke a wide range of emotions in us. Depending on the individual, the ability to manage such emotions varies and can sometimes lead to conditions that impair one's quality of life. The spatially-engaged approach to the study of emotions is well known, especially in the field of human geography (e.g., Davidson et al., 2007; Fahnøe, 2018; Ranta \& Juhila, 2020). According to Bondi et al. (2007, p. 3), emotional experiences and attachments are always located and felt in places and produced in relationships between people and environments. If these feelings are negative, they can lead to avoidance of certain places. Fahnøe (2018) shows how homeless peoples' negative emotional experiences are triggered by certain places, such as homeless hostels or day centres, with certain personal and political dimensions that constitute socio-spatial exclusion from places and services, demonstrating how important it is to examine the clients' emotional reactions connected to leaving home and operating in the community.

Emotional contradictions in floating support work happen for workers as well their clients (e.g., Ferguson, 2010; Muzicant \& Peled, 2018). O'Connor (2020, p. 646), who studied social workers' understandings of emotions in practice, argues that "emotions are inherent in the relational, organizational, and socio-political context of this practice, which involves practitioners working with other people's and their own emotions." She continues: "Emotions are frequently constructed as central to practice, yet at the same time are seen as potentially harmful phenomena which require containment and control" (O'Connor, 2020, p. 646).

Emotions are a major factor in social (care) work, as client-professional encounters often contain challenging topics that can generate powerful feelings in both parties (e.g., Koprowska \& van Nijnatten, 2019). Processing sensitive feelings for both clients and workers goes hand in hand with everyday ethics in professional work (Banks, 2016). Banks (2016) uses the term 'emotion work' as one ethical dimension of professional life when working with vulnerable people. In her description, emotion work contains various aspects, such as "being caring, compassionate, and empathic; managing emotions; building trust; responding to emotions of others" (Banks, 2016, p. 37). In this article we approach the emotion work by means of how workers reflect the client's emotions and respond to them.

The concept of emotion work was originally developed by Hochschild (1979, p. 561), who used it in connection with work environments. Working with emotions means 'managing' them; this is not always successful. In our study, this can mean that a client who feels anxious 
when leaving their home, for example, is helped to identify and process those feelings as they are constructed in certain situations and environments. Hochschild (1979, p. 561) divides emotion work into two types, "evocation, in which the cognitive focus is on a desired feeling which is initially absent, and suppression, in which the cognitive focus is on an undesired feeling which is initially present." When applied to floating support work, this division becomes visible when a client suffering from anxiety either manages to operate outside of the home without the challenging emotion or recognises and labels anxiety as an unsuitable emotion in certain situations or environments. Our demonstration works with the framework proposed by Banks (2016, p. 41), in which she refers to emotion work as an effort people make to both feel certain emotions (e.g., comfort, calm, joy) and to handle emotions (anxiety, fear, or insecurity). In our study, emotion work is seen as a key part of professional social care and floating support work.

\section{The Interactional and Relational Approach to Emotions}

What does it mean to feel anxious, calm, or joy? Are emotions reflections of our inner experiences, memories, and bodily feelings, or are they just biological or neurological processes that can be measured or cured medically? We draw on an interactional and relational approach to identifying emotions (e.g., Gergen, 2009; Hochschild, 1979). Gergen (2009, p. 99) states that "confusion in identifying emotions again suggests that the emotions are not simply there in the head or body to be discovered. Rather, what we call emotion is created in co-action." Simply put, people construct their emotions in relation to certain historical, social, and cultural practices.

Emotions are constructed through psycho-social, bodily, and material relationships and boundaries that are continually present in our daily lives and affect our actions. We are "being moved" by other factors, by other people, art, or beautiful landscapes (Bondi et al., 2007, p. 7). This continuous movement does not only construct pleasant emotions; it also refers to feelings that can threaten our well-being. Emotions "are forms of action that acquire their intelligibility within relationships and... gain their value from their social use. It is not that we 'feel emotions' so much as we do them" (Gergen, 2009, p. 102).

In our study, emotions are 'done' through verbal, bodily, material, and situational interactions between people (e.g., Gergen, 2009, pp. 102-111). For example, when a floating support worker asked a client who has difficulty shopping on his own how it felt when they went to the store together, the client answered: "It was a bit easier." Ease is 'done,' or constructed, in relation to four contexts: in relation to conversation, namely the worker and client describing their feelings on the situation, in relation to floating support and emotion work, when the worker helps the client to manage uncertainty, in relation to the place and action that caused the unwanted emotion, and in relation to a culture in which an adult person is assumed to shop independently.

\section{Methods}

This study draws on the mobile ethnography (e.g., Ferguson, 2016; Novoa, 2015) and discursive approaches (e.g., Hall et al., 2014; Koprowska \& van Nijnatten, 2019). Mobile ethnography emphasises both researcher mobility and mobility in relation to theoretical and analytical perspectives (Novoa, 2015, p. 98); it enables researchers to capture everyday moments in the material world and use their senses during data collection (Ferguson, 2016; Novoa, 2015). This method was utilised to observe how workers and clients interact during floating support visits. Researchers kept diaries of these encounters and audio recorded conversations when appropriate. The discursive approach was utilised to micro-analyse the written and spoken data by focusing on what was said and how it was said regarding emotions, mobility, and leaving the home (Koprowska \& van Nijnatten, 2019, p. 346).

\subsection{Data and Ethics}

Our data consists of transcriptions and field notes gathered during floating support visits that took place either at or outside a client's home (e.g., walks, shopping, bus rides, and visits to the cafeteria). The data was gathered in Finland and England during two separate research projects (the Geohome, "Geographies of Home-based Service Interactions at the Margins of Welfare in Finland and Sweden 2017-2022," and "Responsibilisation of Service Users and Professionals in Mental Health Practices 2011-2016"), both focusing on service encounters at the margins of welfare. Both research projects were approved by the Regional Ethics Committees and all participants gave their informed consent before participating in the study.

The study participants were all adults living independently in their own apartments, either around city areas or close to larger housing units, who have problems related to mental health and/or substance abuse. They needed different levels of support to manage independent living and daily activities. The support visits made by the floating support workers consisted of several kinds of practices, from cleaning or making food to supportive discussions. The educational background of the workers varied from practical and psychiatric nurses to social care students and workers.

The data from Finland was gathered from three floating support services located in three different cities during 2017-2018 while the English data was gathered from two floating support services located in two different cities during 2011-2013. This study focuses on floating support visits that prioritise on clients' mobility and going out into the community. In the first phase of analysis, we coded two data sets from England and Finland 
and looked specifically for home-visit interactions where clients' mobility and need of going out into the community was in focus. After the coding we found 10 support visits from the Finnish data set and nine from the English data set of relevance. These 19 support visits constitute the data analysed in this article. The Finnish data consists of seven support visits with audio recordings (a total of three hours and 39 minutes) and field notes (a total of 10 pages), and three support visits with only field notes (a total of six pages). The English data consists of nine support visits with audio recordings (a total of five hours and 13 minutes) and field notes (a total of 10 pages). Altogether, there were 13 separate clients (one support visit had five clients at the same time) and seven separate workers from Finland and eight separate clients from England. The number of individual workers in the English data was hard to estimate.

\subsection{Analysis}

The analysis was divided into three phases (see Table 1). First, we sorted through the entire data corpus and focused on those parts where workers and clients were either on the move or talking about the movement or mobility. At this point, we were considering the reasons why they were going out to the community, which led us to notice how these visits had different functions regarding movement and mobility. We then analysed the deeper meanings connected to these functions and how the thoughts of leaving one's home or actually being on the move evoked a wide range of emotions, which were then addressed in several ways in client-worker interactions. We then focused on those parts of the data where emotions were talked into being and how these emotions were related to mobility and leaving one's home to visit certain environments. Finally, we identified four separate ways that the emotions were invoked and reflected and defined them as the connections between places and emotions, the emotions connected to leaving one's home, the emotions reflected while being out in the community, and the reflections of emotions after being out in the community. The detailed process of analysis and key contents and interpretations are presented in Table 1.

The next section demonstrates the findings of our analysis through four data excerpts describing how clients' emotions are invoked and reflected in client-worker interactions and the meanings these emotions have in relation to leaving home.

\section{Findings}

\subsection{Connections Between Places and Emotions}

In the following excerpt, a middle-aged woman living alone in an apartment near a supported housing unit talks with a researcher and a support worker after walking in her neighbourhood during a floating support visit. Even though the client lives on her own, she still has access to the supported housing unit and its activities. Her regular support visits usually focus on outdoor activities. The walk is about to end, and the participants are discussing the client's previous and current housing; diverse emotions connected to the clients' earlier residence and current home are revealed:

Researcher: Have you longed to come back here [to the supported housing unit], or is there a big difference now that you live close, but alone?

Client: I can't say I longed to coming back. There was this kind of feeling when living here... a very safe feeling when living in this house [located in the housing unit]. But I get that safe feeling in my own home as well. I'm there behind the locks, alone, so I'm safe.

Worker: If you lived farther away would you feel the same way?

Client: Hard to say, yeah. I might....I think there's some kind of a bond between my life [and the housing unit], as it [housing unit] is so close [to my apartment].

Worker: Yeah, and you are involved in activities there anyway.

Client: Yes.

Worker: This is probably the ideal solution for you.

Researcher: Did it wanting to move away from here come from you, or did it come more from...?

Client: Yes, the care workers recommended it for me as I'm in such good condition and I'll survive, yeah. At first, I did not want to leave this house by any means; I was so attached. But when I left, I was so happy I had gotten my own apartment.

Worker: Yeah, and your own sauna. You went to the sauna very often. And it's lovely that you have a balcony.

The link between place and emotion is constructed when the researcher asks the client, referring to a housing unit, "have you longed to come back here?" The client begins to compare the two forms of housing in relation to safety and recalls that she felt safe while living in the housing unit. However, the client connects the same emotion to her current living situation by saying: "But I get that safe feeling in my own home as well." The emotion of safety is constructed in relation to home, a place culturally associated with security and privacy. In addition, the emotion strengthens as the client elaborates: "I'm there behind the locks, alone, so I'm safe." This seems to imply that the area outside the home is threatening, and that being alone means that no one can hurt her. This conversation 
Table 1. Phases, contents, and interpretations of the analysis.

\begin{tabular}{llc}
\hline Analysis phase & Content & Interpretation \\
\hline $\begin{array}{ll}\text { 1: Concentrating on the parts } \\
\text { where participants were either }\end{array}$ & The mobility involved: & Mobility had functions related to: \\
on the move or talking about the & - regular shopping and other trips & - floating support as a service \\
movement or mobility & that were included in floating & - clients' bodily restrictions \\
& support services & - means to prevent loneliness \\
& - helping clients who had (bodily) & or isolation \\
& disabilities & - sites of learning and managing in \\
& daily life \\
& manporting clients who didn't have & \\
& suffered from fear of social & \\
& encounters & \\
- teaching clients, e.g., going to the & \\
& grocery store to buy food &
\end{tabular}

\section{2: Analysing deeper meanings connected to functions of mobility}

3: Focusing on the emotions and their relationship to mobility and leaving home

\begin{abstract}
Mobility in relation to client-worker interaction:
\end{abstract}

- was used as a tool to discuss diverse topics

- created abilities for clients to learn daily chores

- made insecure situations where clients needed support visible

- enabled thoughts and discussions of how something felt

Emotions are talked into being in relation to:

- cultural perceptions and norms related to home and independent living

- bodily aspects of leaving the home

- temporality: past, present, future

- direct, emotion related questions and positive feedback
Mobility had certain meanings in client-worker interaction:

- created and promoted conversations

- supported psycho-pedagogical actions

- allowed for emotional support

- enabled increased understanding of the emotions and senses of the clients

Emotions are invoked and reflected in client-worker interactions through:

- connections between places and emotions

- emotions connected to leaving one's home

- emotions reflected while being out in the community

- reflections of emotions after being out in the community provides a strong example of why leaving one's home can be difficult.

The link between place and emotion has another meaning as well. After the worker's question regarding whether the client would have the same emotion of safety if she lived further away from the housing unit, the client refers to a bond between her life and the housing unit. The emotion of safety is constructed in relation to the short physical distance between the two places and the activities at the housing unit. The client describes this connection as a 'bond,' a term often used to depict close relationships between people. The researcher asks how the client ended up moving away from the housing unit, and it turns out that previous floating support workers encouraged her to do so, as she was in such good condition and could live on her own. Essentially, the workers used positive feedback as a tool to support the client in the managing of her emotions of insecurity and fears of moving out of the housing unit. The client describes how she had originally resisted the move: "At first, I did not want leave this house by any means; I was so attached. But when I left, I was so happy I had gotten my own apartment." The account reveals both a strong sense of place and an emotional contradiction; there is both a strong attachment to an old apartment and eventual happiness after leaving it. The worker resolves the contradiction and strengthens the client's emotions of happiness by referring to certain spaces (balcony) and activities (going to a sauna), which she uses to help construct an attachment to the client's current apartment and confirm her decision. Overall, this conversation shows the direct, emotion-related impact that the workers can have on clients' emotions and how they relate to place and time. 


\subsection{The Emotions Connected with Leaving One's Home}

The next excerpt pertains to a man in his 40 s who suffers from agoraphobia and serious difficulties leaving his home; he has not really left his house in about 10 years. He usually feels comfortable and enjoys being in his backyard but has not gone very far into his front yard. If he goes too far, his legs start to shake and he starts to feel uncomfortable. He has friends who help him with everyday tasks such as shopping and taking the garbage out. The floating support workers have been asked to help the client gradually leave his property. In this excerpt, the worker and the client are discussing the time the client has spent in his home and how he should proceed in terms of leaving it:

Worker: Yeah, but I think what you need to think about is where do you want to be in 12 months' time?

Client: Well, it's like what I've just been saying in the kitchen, and I know, don't get me wrong, I know I am one of these people where sometimes l'll say a lot of things and you know.

Worker: Put things off a bit.

Client: I put things off, but I do need to motivate myself and start doing these things. And I think one thing that will help me more with outside, it's not because of people looking at me... [unclear] but when I'm out there, I think if I've got like a bit of weight knocked off me it will improve my breathing.

Worker: For your mobility as well.

Client: Yeah, and I won't find that when I'm out I'm saying oh I need to go back in because blah, blah, blah. I feel as though I'd be able to stay out more.

Worker: But there's got to come a point when you've got to say to yourself, right, this is when it's going to change.

Client: Yeah, I know.

Worker: I mean, if you're serious enough about it, and I think you are.

Client: Yeah, well the thing is I am, and I don't want to stay like this.

Worker: It's been how long now, 10 years?

Client: Yeah, because I was thinking about this the other day.

Worker: It's a long time [name].
Client: Because I thought, well you're 41 now, you're going to be 42 in September, you can't keep wasting the years.

Worker: See those 10 years, you'll never get those back.

Client: Exactly, so it's something that I need to do, but I think first things first, what l'm going to do, what I'm going to get sorted, and I am going to get it sorted as well, I'm going to sort my house out, get it tidied, and I am going to get it tidied.

Worker: Well, I mean it's all part of, like, a new beginning, if you like.

Client: Yeah, get my house sorted out, but also I'm going to start going on the [indoor] bike, I'm going to start going on the bike again and work at going on the bike, because after a week of me going on the bike I do feel better. But I'm going to stick with it, and I am going to do it, and I'll let you know how I get on. I will tell you, I won't lie to you.

Worker: No.

Client: I'll tell you the truth, but I think if I just go on the bike a little bit and just feel that bit better in myself, I reckon I'll be more up for.

Worker: Yeah, you've got to look at the positive side, just what benefits you'll gain from it.

Client: So yeah, I am going to do it, and I mean that as well, I'm not saying it and then like oh I can't do it. My back does hurt me still, I do have problems with it, but it's not like it was when I had problems getting out of bed.

Worker: Like you say, if you lost a bit of weight that [would] probably [help].

Client: Well, that's why I want to go on the bike.

Worker: Yeah.

This discussion begins with the worker's rather direct address: "What you need to think about is where do you want to be in 12 months' time." The term 'need' constructs an emotion of seriousness in relation to the client's situation and his time spent inside the house. The client attributes his actions to being the kind of person who "put things off a bit," as the worker concludes. The client affirms this and agrees: "I do need to motivate myself and start doing these things." The client's reference to motivation and the need to do something constructs a vague reluctance or stagnation in relation to leaving his home, but also reflects how he feels the necessity 
to do something about it. However, the client has an idea of how to increase his motivation. He explains that the reluctance to leaving his house is not connected to the people outside, but rather to the emotions constructed in relation to bodily aspects, such as weight and breathing. The worker confirms the client's pondering on the benefits of weight loss and adds that it would also help his mobility, referring to both bodily mobility and movement within the community. The client agrees: "Yeah, and I won't find that when I'm out I'm saying oh I need to go back in because blah, blah, blah. I feel as though I'd be able to stay out more." He constructs an emotion of inability in relation to being outside the home environment, which would be improved if he lost some weight.

The worker transfers the responsibility of change to the client by saying that "there's got to come a point when you've got to say to yourself, 'right, this is when it's going to change.'" This expression constructs emotions of decisiveness and self-reliance, as if leaving home is a choice that needs to be made. The worker continues: "I mean, if you're serious enough about it, and I think you are." The client confirms: "Yeah, well, the thing is I am, and I don't want to stay like this." The discussion continues by focusing on the past 10 years, which the client has spent in his home. This reflects the earlier construction regarding the emotion of leaving home as a choice based on whether the client is sufficiently serious about wanting the change in his life; this illustrates the complexity of the situation. The client does not want to stay like this, but who or what prevents him from making the choice to leave home? The worker goes on to state that the client can't keep wasting the years; these strong impressions reflect the strong emotions connected to misplaced life and the necessity to fix the situation.

The client agrees and offers new ideas for improving his motivation to leave home. The client's accounts of the emotions of credibility and commitment to leaving the house are constructed in relation to concrete actions, such as tidying the house, indoor biking, and promises of commitment. The client shows that he is seriously trying with this talk of planning, but these acts would also be a very demanding lifestyle change compared the duration of his situation. Still, the worker constructs an emotion of hope by saying: "Yeah, you've got to look at the positive side, just what benefits you'll gain from it." The client responds by confirming that he will do it, despite his back problems. Overall, this excerpt demonstrates the client's fear of open places and illustrates the equivocal emotions tied to temporal, bodily aspects as well as the cultural norms related to leaving one's home and the difficulty in disentangling them.

\subsection{The Emotions Reflected While Being Out in the Community}

In the next excerpt, a worker and a male client are talking while walking down the street. Significant background noise complicated the transcription of the conversation.
The client has had difficulties leaving his house since his wife passed away three years ago. In a separate interview, the client told the researcher that he had no contact with other people and was in his 'comfort zone' after his wife died. Additionally, his previously diagnosed anxiety only got worse after his wife's death. Within the last year, he has been able to go out with the help of the floating support team. Thus, the aim of the service in this case was to get the client out of his home. The client told the researcher that he needed a distraction to avoid anxiety attacks:

Client: Yeah, so I mean that's, how weird it is now because I was, I mean I told you there [unclear] it's because you're anxious because you haven't done it. I was a bit wary thinking, oh no, you're not going there today, but you don't exactly have to do it because otherwise you'd never conquer.

Worker: Well, that's it yes, of course.

Client: You get anxious but, well without, when you said like go to the bank, it was like oh yeah. But come Monday yeah, because I know exactly you need to do it, so yeah.

Worker: It's been good so far, because I think we've, I mean, today, I didn't expect us to progress any further than we have been, but previous to this we've always gone further.

Client: It's funny as well, because when I used to have that fear, my hands sweating and things like that, you know the first one we ever did, the cafe.

Worker: Yes, on the corner.

Client: Yeah...[unclear] I don't even think I could easily walk and it doesn't register anymore.

Worker: There was a time when...

Client: I couldn't imagine that as well like...[unclear word] that long road.

Worker: Oh, it's amazing.

Client: I've cycled it...

Worker: Are you still using public transport?

Client: Taxi.... had no problem whatsoever, I've never been on a bus...[unclear] so yes I do, I mean...

Worker: Well, one thing at a time.

The client first considers that even the thought of going into the community can construct an emotion of 
wariness or anxiety, but that these emotions can be resisted by being aware of the fact that the only way to conquer them is to go. The worker provides positive feedback by saying: "It's been good so far because I think we've, I mean today, I didn't expect us to progress any further than we have been." This expression provides a concrete example of how mobility and being in the community can be used as a tool to track the client's progress. The emotion of joy related to client's progress is constructed in relation to the positive feedback and the milieu where the client and the worker are walking.

The worker inspires the client to remember the physical reactions he had when the floating support visits began: "I used to have that fear, my hands sweating and things like that, you know the first one we ever did, the cafe." These emotions of fear are constructed in relation to a certain cafe on the corner, as the worker confirms. Recalling their earlier visits in the community concretises the client's proceeding, as he states, "Yeah...[unclear] I don't even think I could easily walk, and it doesn't register anymore." Fear transformed into ease, which is amazing, as the worker describes. However, despite the good progress, there seem to be new challenges to overcome. The discussion transfers from walking to riding the bus when the worker asks about public transport. The client says that he did not have problems using taxis but that he had "never been on a bus." Based on their conversation, it could be assumed that future bus rides could cause the same kind of emotions as that first walk to the cafe. The client seems cautious, but willing to try a bus ride when he says: "I do, I mean." The worker supports the clients' thoughts and constructs the emotion of calmness in relation to gradual progress by saying: "Well, one thing at a time." Overall, this excerpt illustrates how being out in the community invokes variety of inconsistent emotions and bodily reactions that change over time and based on the clients' condition.

\subsection{Reflections of Emotions after Being Out in the Community}

In the next excerpt, the client in his early 30s, worker, and a researcher went to a grocery store together. Shopping is difficult for the client because he has a hard time making choices and deciding what to buy; he also suffers from depression and anxiety. One aim of the floating support visits is to help him cope independently with daily chores. In the excerpt, the worker and client are reflecting on the shopping trip after returning from the store:

Worker: How do you feel after we were with you at the grocery store? Was it different than when you go there alone?

Client: Yes, there was a small difference.

Worker: How did it differ?
Client: I don't know, I talked to people more. Usually I don't say anything.

Worker: But did it feel that... was it harder to be in the store or did it make it easier? Did it have any influence on that?

Client: It was somehow easier or... although you didn't suggest anything or the like...

Worker: What do you think, what made it easier?

Client: Hmmmm...

Worker: Was it easier to make decisions, although we didn't suggest anything? Or was it just easier to be in the store? What do you think?

Client: Well, maybe that, if it was hard to decide or I didn't know how to decide, there was someone to ask instead of pondering it by myself for an eternity.

Worker: Yeah, yeah. So that you weren't required to ask but knew that you could if you needed to. Okay. If you go shopping, just to get something, whatever, like food, do you have that same feeling, that it would be nice if there was someone you could ask?

Client: I don't know about the grocery store, maybe, but I don't go to other kinds of stores so often. It sort of depends.

Worker: But, for example, we went to H\&M once, and you had been there by yourself but hadn't found anything, and then once we went together you bought that shirt. Did it feel easier? Well, I guided you to ask a salesperson, and then you asked, and the shirt was found. Was it easier when I was with you?

Client: Yes, at least in the clothing store.

Worker: So is it that, that you feel insecure, this is just an idea, tell me if I'm off track. But do you feel insecure because you don't know what you are making decisions about?

Client: Yes, fairly. It's hard to make decisions. Especially with clothes....I've sometimes bought things that didn't fit.

Worker: Do you have that same insecurity in the grocery store? Do you think that you are going to make a mistake when buying something?

Client: In the grocery store, it's more that I don't fancy anything specific and the selection is large. So that's [laughs] great. 
Worker: You have talked about earlier, that going to the store is difficult for you. Especially going to the grocery store. You have said that you have to go to the grocery store quite often because you can't plan what to buy for the next several days. So, [you buy] what you fancy at that moment. But what do you think, would you like us to go to the store together more? Say if it's something you wouldn't like; it is just an idea.

Client: I don't know, why not? But it is not necessary.

The worker inspires the client to talk about his emotions related to shopping when she asks: "How do you feel after we were with you at the grocery store? Was it different than when you go there alone?" The client admits that there was a small difference, but he seems to have trouble specifying. However, he notices that he spoke to people more. The worker continues to discuss his emotions, asking: "But did it feel that... was it harder to be in the store or did it make it easier? Did it have any influence on that?" Difficulty and ease are constructed in relation to the store and the presence of the worker and the researcher. Specifying emotions connected to shopping still seems difficult for the client, but he believes that being in the store was easier. The worker continues with more specific questions concerning the emotion of ease, which can be interpreted as both trying to help the client recognise certain emotions and trying to help them determine the factors that could help him engage in the community in the future. Finally, the client connects the ease to the emotion of comfort to making decisions while shopping and describes how being in the store would be easier if "there was someone to ask instead of pondering it by [himself] for an eternity." The term 'eternity' highlights both the client's difficulty in making decisions and the intention of the floating support visits.

The worker reacts to the client's account and further specifies by asking whether there were any differences between shopping in different stores. The client hesitates and the worker brings up an earlier trip to the clothing store, recalling how the client did not manage to buy a shirt alone but succeeded when they went to the store together. The worker continues to ask about the clients' insecurity in decision making and constructs it in a very sensitive way by asking the client to clarify whether the worker was off track. By this, the worker can avoid implying that they know how the client feels and offer the client the possibility of disagreeing or explaining. However, the client agrees: "Yes, fairly. It's hard to make decisions. Especially with clothes....I've sometimes bought things that didn't fit." The fear of making mistakes mixes with emotions of insecurity and to the difficulty with making decisions. The worker also offers a solution by asking whether the client would like the idea of them going to the store together more often. The emotions of respect and free will are constructed in relation to the client's subjectivity and autonomy. This excerpt illustrates the potential difficulty in having these conversations and the importance of recognising the different emotions related to places and activities. It also reflects cultural perceptions and expectations of an independent adult who can make their own decisions.

\section{Discussion and Conclusion}

This study demonstrates how various place-related emotions are constructed and reflected in client-worker interactions. We have shown how emotions are made visible in communicated actions (Koprowska \& van Nijnatten, 2019) and in relation to the socio-cultural contexts in which people operate daily (Gergen, 2009). In this study, the socio-cultural context is the normative presumption that adults should be able to live independently and leave their homes without difficulty. Our study demonstrates that living according these requirements can be contractionary and that emotions have a significant meaning for vulnerable people and the promotion of their social inclusion.

During the client-worker interactions, feelings of security to fear or despair to hope were situationally and continually constructed. This confirms how emotion work (Banks, 2016; Hochschild, 1979) is an inseparable part of floating support work. The biggest surprise was that explicit emotional expressions (e.g., "today I feel..." or "it felt really...") connected to certain places and environments were rather rare in the discussions. The clients seemed to have difficulties with spontaneously talking about their emotions. However, the workers helped the clients specify and recognise their place-related feelings and manage the emotions that prevented them from leaving their homes. They walked on the streets and in nearby neighbourhoods with the clients, made plans about how to proceed step-by-step, and went to stores with them. These practices made it possible for them to influence the emotions that prevent clients from leaving their homes and make their progress more visible. It was also notable that, in some cases, it was not the place or environment that brought up the difficult feelings, but rather the socio-cultural practices maintained there (e.g., riding the bus or buying clothes). Authors have shown how floating support work at the margins of community care is connected to situationality, boundlessness, and empathy (Juhila, Hansen Löfstrand, \& Raitakari, 2020). In the core are activities that cover diverse aspects and needs of everyday life. Our study adds the idea that emotion work is a necessary activity and a key part of promoting clients' social inclusion.

Our findings reflect Fahnøe's (2018) position that strong place-related emotions, like fears, uncertainty or physical affections, can be so comprehensive that staying home and avoiding them can offer a form of self-protection. Nevertheless, our data demonstrates how clients actively work with their contradictory placerelated emotions and how willing they are to be able to act in the communities. We argue that learning to leave 
the safety of the home and go out into the community requires time and commitment from both clients and floating support workers. We conclude that future policy should consider that going out to the community can require very demanding lifestyle changes from people living at the margins of welfare, and to recognise the importance of floating support services in the future as well.

\section{Acknowledgments}

The authors would like to thank all the clients and workers who kindly participated in the two separate research projects granted by the Academy of Finland (decision numbers 307661 and 250221). Moreover, the authors would like to thank effort and contributions made by all the other members in the Geohome-project.

\section{Conflict of Interests}

The authors declare no conflict of interests.

\section{References}

Banks, S. (2016). Everyday ethics in professional social work: Social work as ethics work. Ethics and Social Welfare, 10(1), 35-52.

Bondi, L., Davidson, J., \& Smith, M. (2007). Introduction: Geography's 'emotional turn.' In J. Davidson, L. Bondi, \& M. Smith (Eds.), Emotional geographies (Vol. 1, pp. 1-16). Ashgate.

Davidson, J., Bondi, L., \& Smith, M. (Eds.). (2007). Emotional geographies. Ashgate.

De Heer-Wunderink, C., Visser, E., Sytema, S., \& Wiersma, D. (2012). Social inclusion of people with severe mental illness living in community housing programs. Psychiatric Services, 63(11), 1102-1107.

Fahnøe, K. (2018). Emotional geographies of urban homeless people's avoidance of places providing social services. European Journal of Homelessness, 12(2), 15-34.

Fakhoury, W., \& Priebe, S. (2007). Deinstitutionalization and reinstitutionalization: Major changes in the provision of mental healthcare. Psychiatry, 6(8), 313-316.

Ferguson, H. (2010). Walks, home visits and atmospheres: Risk and the everyday practices and mobilities of social work and child protection. British Journal of Social Work, 40(4), 1100-1117.

Ferguson, H. (2016). Researching social work practise close up: Using ethnographic methods to understand encounters between social workers, children and families. British Journal of Social Work, 46(1), 153-168.

Gergen, K. J. (2009). Relational being. Beyond self and community. Oxford University Press.

Hall, C., Juhila, K., Matarase, M., \& van Nijnatten, C. (Eds.). (2014). Analysing social work communication: Discourse in practise. Routledge.

Hall, C., Raitakari, S., \& Juhila, K. (2021). Deinstitutionalisation and 'home turn' policies: Promoting or hampering social inclusion? Social Inclusion, 9(3), 179-189.

Hare-Duke, L. (2017). The importance of social ties in mental health. Mental Health and Social Inclusion, 21(5), 264-270.

Hochschild, A. R. (1979). Emotion work, feeling rules, and social structure. American Journal of Sociology, 85(3), 551-575.

Juhila, K., Hansen Löfstrand, C., \& Raitakari, S. (2020). Devoted work without limits? Activities and premises of home visit work at the margins of community care. International Journal of Care and Caring, 5(2), 247-262.

Juhila, K., Holmberg, S., Lydahl, D., \& Hall, C. (2020). Observing and commenting on clients' home environments in mobile support home visit interactions: Institutional gaze, normalization and face-work. Housing, Theory and Society. Advance online publication. https://doi.org/10.1080/14036096.2020. 1838944

Koprowska, J., \& van Nijnatten, C. (2019). Emotion and discourse: Analysing social work up close. Journal of Social Work Practice, 33(4), 363-368.

Kröger, T., \& Leinonen, A. (2012). Transformation by stealth: The retargeting of home care in Finland. Health and Social Care in the Community, 20(3), 319-327.

Miettinen, S., \& Teittinen, A. (2014). Deinstitutionalization of people with intellectual disabilities in Finland: A political perspective. Scandinavian Journal of Disability Research, 16(1), 59-76.

Muzicant, A., \& Peled, E. (2018). Home visits in social work: From disembodiment to embodied presence. British Journal of Social Work, 48(3), 826-842.

Novoa, A. (2015). Mobile ethnography: Emergence, techniques and its importance to geography. Human Geographies: Journal of Studies and Research in Human Geography, 9(1), 97-107.

O'Connor, L. (2020). How social workers understand and use their emotions in practise: A thematic synthesis literature review. Qualitative Social Work, 19(4), 645-662.

Ranta, J., \& Juhila, K. (2020). Constructing a sense of home in floating support for people using drugs. Qualitative Social Work, 19(4), 685-700.

Richardson, J. (2019). Place and identity. The performance of home. Routledge.

Tideman, M., \& Tossebro, J. (2002). A comparison on the living conditions for intellectually disabled people in Norway and Sweden: Present situation and changes following the national reforms in the 1990's. Scandinavian Journal of Disability Research, 4(1), 24-42.

Tucker, I. (2010). Mental health service user territories: Enacting 'safe spaces' in the community. Health, 14(4), 434-448.

Wong, Y.-L. I., Stanton, M. C., \& Sands, R. G. (2014). Rethinking social inclusion: Experiences of persons in recovery from mental illness. American Journal of Orthopsychiatry, 84(6), 685-695. 


\section{About the Authors}

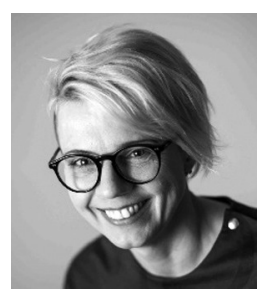

Suvi Holmberg works as a university Lecturer at the Faculty of Social Sciences, Tampere University. Her special research interests concern issues related to sociocultural meanings of illness and everyday life with somatic (especially cancer) and mental illnesses. Her methodological interests are based on qualitative health research, mobile ethnography, and discursive methods. She is a member of the Multidisciplinary Psychosocial Cancer Research Group and Margi Research Group.

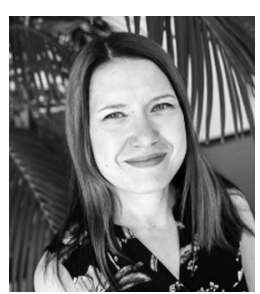

Jenni-Mari Räsänen is a university Lecturer at the Faculty of Social Sciences, Tampere University. Her main research interests concern the issues of recording, the transferring of information, integrated work, home visits, professional responsibilities and boundaries in different mental health and social work practices. Her methodological interests are based on ethnomethodological studies of talk and interaction. She is a member of the Margi Research Group. 